\title{
Policies and issues in urban development in Sri Lanka: an examination of the inter-domain gaps
}

\author{
Jagath Munasinghe \\ Department of Town \& Country Planning, Faculty of Architecture, University of Moratuwa, Moratuwa
}

\begin{abstract}
This paper focuses on the issues with the current policies in urban development in Sri Lanka. Although much has been discussed on urban development related issues for many years, more attention of both the policy makers and the research community is needed since no significant improvements in connecting research, policy and practice are observed within the sector. Finding solutions for the problems at the roots of these issues is not an easy task, but a discourse on them is timely for improved awareness of those who are interested and affected. In order to contribute towards that, attention is drawn to the issues surging from the gaps in three areas: urban management, traffic management and adaptation to climate change effects, which are among the main concerns for present day urban development in Sri Lanka. In order to conceptualize the complex relationships between the policies, practices and research findings, the paper adopts a simple rational model of actors involved in the policy formulation processes which are divided into four mutually exclusive domains: research communities, interest groups, policy makers and the society. The paper highlights that many of the issues are surging from the gaps in between these four domains and hitherto the problems associated with the transfer of knowledge emanate from research findings, inevitable ground realities that are not reflected in policies, conflicts between the policy intentions and the social interests, and the perceptual differences among researchers, policy makers and the social groups.
\end{abstract}

Keywords: Interest groups, perceptual differences, policy formulation, urban development

\section{INTRODUCTION}

The current urban development trends and patterns in Sri Lanka (similar to many other countries) paved the way towards many complex issues, which in some way or the other are connected to policies. Although much has been discussed on these issues (eg: Perera \& Gunaratna, 1995; Kurukulasuriya, 1997; UDA, 1998; Gunaratne, 2006) for many years, greater attention of both the policy makers and research communities is required in the field as no significant improvements to the situations are observed to date. Finding clear cut solutions for all problems at the roots of these issues is far from a possibility, but a wider discourse on them is timely at least for the benefit of those who are interested and affected. In order to contribute towards that, this paper draws the attention to a few issues surging from the gaps, pertaining to research outcomes, ongoing practices and the policy formulation in the urban development sector in Sri Lanka.

As stated earlier, scholarly work on urban development issues are not rare, but a majority of these have focused upon specific aspects such as waste management (Perera, 2011), urban heat islands (Emmanuel, 1995), traffic management (Bandara, Lo \& Wong, 2006), etc. At the same time, these studies viewed problem situations more on technical grounds, divorced from the policy and the social context entangled with them. Hence, the attention paid on the impact of public policy and research on these issues and their implications on society at large is limited, despite the increasing importance for such studies. This study is an attempt to address this limitation in the urban development sector through a conceptual approach.

It is admitted that the relationships between scientific research, public policy and the society are sustained through complex processes, but not with technically simulative simple procedures (Weiss, 1991; Oh, 1997). Yet, the knowledge-driven or problem-solving based models, widely adopted in social sciences, are still useful to gain a general understanding of this relationship. Out 
of what is presented in literature, this relationship could be modelled as in the following figure relating to four conceptual domains that sorround decision processes. These four domains are not mutually exclusive, but are largely integrated and indivisible, while the links between them are reciprocal.

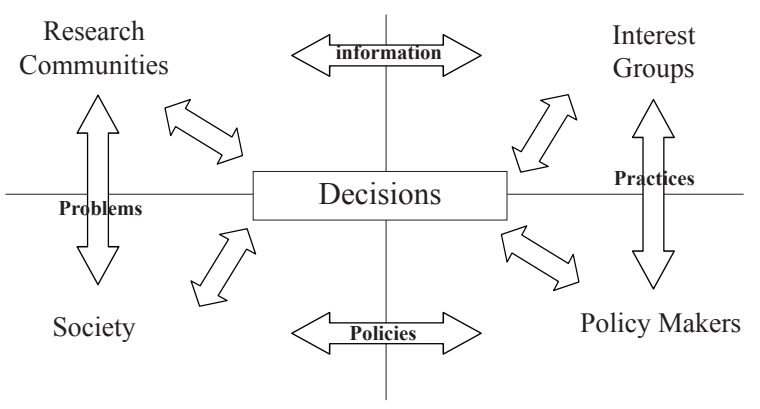

Figure 1: Relationship of conceptual domains

Accordingly, research produces knowledge that is used in the form of data and information by the decision makers, either to make decisions or to legitimize decisions, but not directly for policy changes (Oh, 1991). Yet accumulated knowledge is incorporated into practices through the process of 'enlightenment' of interest groups. The reverse is also possible, where research activities are promoted by some interest groups and decision makers. When the interest groups are strong enough to influence decision making processes, then the knowledge on certain practices are diffused into policy discourse through networks of influence. The practices may then turn into policies either within a short period of time or as incremental changes over a longer period of many years, involving social and political persuasions (Hall, 1990; Weiss, 1991), or perhaps banned due to their inconsistency with political agendas. Both may happen either in the form of introducing new policies or in terms of making changes to existing ones. When policies are in place, their effectuation impacts the society at large, by influencing activity patterns and life styles. The society may either adhere to the policies or resist them, depending on their impact on prevalent or emerging practices in society. The levels of adherence or resistance bring in certain issues to the notice of decision makers necessitating timely reviews of the policies. In such instances the policy makers are compelled either to change policies or to turn to research groups, depending on the importance of the issues perceived through 'policy paradigms' (Hall, 1990). Sometimes the research groups may develop self interests to undertake research on such issues. The process is not necessarily one way, but it may have both forward and backward movements.

This model indeed, can be regarded as hypothetical and idealistic, as this type of 'rational' models do not necessarily reflect the real world relationships between research and policy (Clay \& Schaffer, 1984; Hall,1990), but it provides us with a conceptual framework to comprehend many events in our society relating to research and policy with some level of distinction, avoiding the myriad of complications. As an example, the research finding that the intake of more carbohydrates could lead to health problems, compelled certain affluent middle class groups in Sri Lanka to switch to grainy foods such as rice flour, etc; over the last two decades. This practice influenced the relevant state authorities and by 2010 , a policy was framed to discourage wheat flour products in primary and secondary schools and health institutions. Finding substitutes to wheat flour products was an issue for many groups who were highly used to them and thus, the authorities and the food producers are now urged to find alternatives through research.

The essential proposition here is that, if the loop is well connected to all of its links, then there are no gaps between different domains and therefore, the flow is smooth. The problem we experience today is the gaps between these domains. When viewed from this framework, the gaps in urban development research-public policy relations can be identified in four different sets. The forthcoming sections of the paper discusses these gaps with special references to three of the mostly discussed subject areas: urban management, urban transportation and adaptation to climate change effects, which are currently posing various challenges to urban development both in Sri Lanka and in other countries.

\section{PROBLEMS IN KNOWLEDGE TRANSFER: GAPS BETWEEN RESEARCH COMMUNITIES AND INTEREST GROUPS}

The gaps between research communities and interest groups inhibit the transfer of knowledge, which emerge from research findings which is instrumental in the formulation of new practices. In Sri Lanka, urban development related research is undertaken by three different types of organizations. The first is academic institutions, mainly universities that produce a number of commendable research projects, both as students' work and independent academic projects. The second are the urban development and related agencies such as the Urban Development Authority, National Physical Planning Department, Ministry of Environment, National Building Research Organization, Ministry of Transportation, etc. who occasionally undertake research on specific areas of their interest. The third is the independent research institutes and a few individuals engaged in a variety of research activities. In addition to those, a large number of international research journals are available and they 
bring in a voluminous body of interesting and useful findings on urban development related issues every year. However, the main problem noticeable with all these sources is the inadequate communication of their findings to the outside communities. Even though some research in academic institutions could initiate certain kinds of practices, they have been limited to those institutions. For example, improved techniques and methods supported by research findings are common nowadays in university design studios for urban analysis for planning, management and design activities. Student projects are illuminated with those techniques leading to excellent results. Yet, the urban development agencies still depend largely upon conventional methods and techniques, which have been proved to have had many limitations.

At the same time, inadequate collaboration among research agencies in undertaking research is also evident. Urban management issues such as attracting investments, service delivery, waste disposal, public participation in governance, etc. have been topics discussed throughout by all three types of agencies for many years. In spite of the large number of publications on sets of different issues ${ }^{1}$, the knowledge and expertise are still gathered in isolated projects, rather than collaborating at national level programmes. Therefore, a base to develop a wider interest on good urban management practices among relevant authorities in Sri Lanka is not yet apparent. Fragmentation prevents the formation of a coherent body of knowledge within the field and this in turn, inhibits the development of interests among the needy.

Fragmentation is also observed in the urban transportation sector, in which some work proposes reduced inflow of motor vehicles into the city and to promote improved public transport measures such as 'park-n-ride' (UDA, 2001), alternative choice models (Kumarage, 2004) and bus rapid transit system (Embarq, 2009) etc, while the others have engaged in alternative route modelling and simulations to enable the easy flow of traffic into the city. Both are in search of methods to address issues emerging from the increased use of motor vehicles. A few projects could go to the extent of trial applications (eg: Park n Ride), while most of them remain unknown to many. Similarly, while some work emphasized the fact that provision of parking facilities encourage traffic in core areas (Diandas, 1995), others were interested in suitability options for car parks within the city viewing that the present inflows are inevitable. This indicates a dual orientation in research, while the consequences of this duality and the resulting practices are somewhat evident today with the large parking facilities provided at the core areas of some cities (eg: in Kandy City Centre).
Climate change effects and adaptation is a hot topic at present and many organizations have undertaken research in this area. Urban development is regarded as a sector that is most affected by climate change and also responsible for implementing strategies for adaptation. The Ministry concerned has taken a special interest on climate change and related issues and it hosted a number of publications, workshops and conferences over the last few years ${ }^{2}$. Even though urban development agencies were among the co-participants of these events, a significant move in the sector is not seen to date.

One of the known, but less discussed reasons behind the confinement of knowledge into containers is the absence of communication and the reluctance for collaborations among different institutions and individuals engaged in research. The individuals are driven by ego-centric objectives that warranted authorship more than the outcome of the ventures. When the objectives are self-oriented they naturally devalue opportunities for collaboration and hitch-hiking possibilities in research. Reasons for the non-penetration of knowledge into practicing and policy arenas include: bureaucratic establishments within the organizations that resist new knowledge (Self, 1985) and the conservativeness that embraces the organizations with their maturity, that make them reluctant to change (Oh, 1997).

\section{INEVITABLE REALITIES: GAPS BETWEEN INTEREST GROUPS AND POLICY MAKERS}

Ground realities such as resource constraints, the partiality of decision makers and the lack of voice for the weaker, created gaps between interest groups and the policy makers. This gap leaves less space for good practices to emerge and appropriate policies to be formulated. The present day urban development activities in Sri Lanka are mainly implicated by the directives of Urban Development Authority (UDA). Concurrently, Sri Lanka's local government policy envisions to recognize 'local governments as autonomous bodies by empowering them with needy manpower, financial and decision making powers' ${ }^{3}$ and the local authorities too need the prompt effectuation of the policy (Abeywardane, 1999). To this end, local authorities are vested with substantial powers to plan and regulate 'area based' developments within the area of their jurisdictions ${ }^{4}$. However, planning and regulation of developments need higher level of competencies for a broader understanding on the development potentials of the respective geographic entities, their use in conformity with the national policies, their impact on environmental conditions, and many other aspects. In the absence of such competencies, 
planning and regulatory processes are presently handled by the UDA, which has a centrally controlled, top-down mechanism. While the role of the local authority in urban development is limited to a few technicalities, the two agencies are often seen having uncomfortable sittings with each other at decision making. Even though a high level of autonomy is the interest, inadequate resources have constrained policies from turning into practices.

A similar duality is also observed in the transportation sector, which is a key function of urban development. The magnitude of the problems in urban transportation can be sensed with the finding that more than twothirds of the road space in urban areas are being used by less than one third of those who use hired and private vehicles, while only one fifth of the roads space are being given to the other two-thirds (Diandas, 1995; EMBARQ, 2009). These complications were addressed by several proposals seeking better scenarios for urban development such as alternative transportation modes (Kumarage, 2004), bus rapid transport system (EMBARQ, 2009), etc. Encouraging the use of public transport and walking are often stated as 'good practices' for better quality of life in urban environments. Quite contrary to the findings and the advocacies, the relaxed policies of the government on motor vehicle import and ownership promotes more and more private cars on the road, aggravating the problem rather than promoting good practices. When transportation at the urban level is considered, policies imply a priority order: the pedestrian: the first, the cyclist: the second and motor vehicle: the last (Diandas, 1995; NPPD ${ }^{5}$ ). At the same time, urban design projects envision livable, workable and enjoyable urban environments for all user groups of whom the majority are pedestrians that use public transportation modes. Still, the road development activities of the relevant authorities seem to be more in favour of facilitating vehicles rather than comforting the pedestrians and cyclists, as the roads are designed with least possible space for the latter. An unpublished studio work in recent years in the University of Moratuwa ${ }^{6}$, revealed that a higher percentage of the streets in Colombo and other cities did not have sidewalks. The macadam paving up to the shoulder edge of the roads with no differentiated paving for sidewalks had been detrimental to pedestrians as the entire road space was used by motor vehicles either for movement or for parking. Adding to this, the recent traffic management strategies devised with the support of Sri Lanka Police that included making more roads one way to ease the flow, shifting bus halts, etc., are in favour of the minority that uses vehicles. Although in-depth studies on the impacts of this Act have yet to be found, it has undoubtedly imposed a burden on the users of public transport, who composed the overwhelming majority of the commuters. They are compelled to walk far to get to their destination and wander to find bus routes, bus stops, road crossings, etc (Kumarage, 2011). Clearly the traffic management practices at this instance reveal a deviation from the general policy in the absence of a voice for the weaker, who is still the majority.

These situations show the inconsistencies between what is there in the policy and what is being practiced. Preferred practices, however much supported by interests, could not adequately influence policy agents, while the policies may not necessarily be in practice for a variety of reasons. On one hand, the link between interest groups and policy makers as well as the latter and the enforcing agents are not that smooth. On the other, policy framing too is somewhat fragmented among national level organizations. The need, therefore, is a strong nexus between research groups, policy makers and the implementing agents. A good sign towards this from recent times is the increased engagement of research done as consultants in many ministries, public organizations and development agencies. This may be a good opportunity to infuse better and more versatile practices into policies. If they are able to influence policy making processes, then the impasse is not that hard to break. However, they will have to deal with the obstacles such as politics that play the major role in making choices, incompetence and resistance of the bureaucracy to newly emerging knowledge and the resource constraints within implementing agencies to initiate and sustain good practices. (Self, 1985)

\section{CONFLICTING INTERESTS: GAPS BETWEEN POLICY MAKERS AND THE SOCIETY}

The gaps observed between policy intentions and the general social interests seem to be resulting in another set of issues. The crucial gaps are well seen today with the issues related to solid waste disposal, which has become a riddle in urban management. The government has introduced many policies and encouraged practices such as reducing the use of polythene and plastics, sorting waste at generation, recycling of waste materials, use of compost bins, etc ${ }^{7}$. These practices are supported by many interest groups and a large number of private business organizations. However, the success rate of these practices is not impressive since the message is not that well received by the society in general. An interesting example in this regard is found in a recent case related to polythene products, which have been among the top trouble makers in both urban and non- 
urban environments in Sri Lanka. Polythene products are often shown as a demonized material, but quite attractive to the users for their versatility, cheap availability and perhaps, relatively better durability. The havocs they evidently create in the environment include severe drain blockages, non-degradable waste accumulation, mosquito breading, danger to wildlife and many more. In one of the instances, a practice introduced by leading supermarket chains in the country with the blessings of the relevant ministry, to levy a fee on polythene bags in order to discourage the use was challenged by a citizens group and ruled out through a court order ${ }^{8}$. This, in some way, indicates a conflict between the interests of the policy making agencies and the general public.

Another set of conflicting interests is observable with the National Physical Planning Policy, which is supposed to be the supreme national level policy that deals with urban development related issues in Sri Lanka. The policy was formulated by the National Physical Planning Department based on the findings of a stream of research activities. The policy has covered a wider range of interests including urban development, infrastructure provision, transportation and connectivity improvement, environment conservation, land use distribution, etc. It advocates an urban development strategy that will constrain physical development activities in the fragile areas (central hills) of Sri Lanka with the intention of preserving the water catchment of the island. In order to accommodate continuous trends of urbanization, it indicated a few metropolitan growth areas scattered mostly in the dry zone of the country (NPPD, 2009). The policy has clearly addressed the problem of the endangered water catchment of the island. However, it is observed that the policy was not known to many, even among affluent agencies and interest groups of the society. The problem generally discussed and highlighted more often than not is the difficulties presently experienced in the means of accessing the central areas of the island. Therefore, the authorities responsible for road transportation proposed an expressway to the city of Kandy along with many highways in the central hills ${ }^{9}$. As the generally accepted norm is that higher accessibility to a location leads it to have a greater potential for urban development (Leda, 2010), the improved access to central hills may open up possibilities for rapid urbanization in those areas. Thus, there seems to be an inconsistency between the authorities involved in physical planning and road development although both work for national and social interest. Similarly, the national projects related to urban infrastructure such as electricity, water supply and road construction formulated by related agencies in many cases are blind towards the main national physical planning policy. Upon political pressure, immediate needs of certain local groups and demand clusters are addressed instead of discouraging the developments in any environmentally sensitive locations in the island.

Research on climate change revealed that a substantial part of our coastal areas are vulnerable to the effects of the rise of sea level and many others in the central hills are vulnerable to landslides, etc. It is also noted that more than seventy percent of the urban population in Sri Lanka are living in these urban areas of the coast and the hills (Census, 2001). The National Physical Planning Policy addressed this issue by means of providing some directives for future urban development. Yet, this has not influenced the mainstream political ideologies to redirect urban development from the coastal belt and the central hills to elsewhere. When information of the national census is compared, the coastal urban areas have grown by nearly sixty percent in terms of population increase between 1971 and 2001, and this figure is almost twice the size of the same of all non-coastal towns. The trend has not changed much over the last ten years and a clearer picture of this will be possible with the findings of the 2011 census. Thus, the research findings and the urban development related policies have less effect on the preferred residential location choices of the society that gears the prevailing urban development trends in the island.

The most recent political advancements in Sri Lanka in which urban development is a subject under the national defense portfolio of the central government, may be regarded as a landmark event and signifies a positive turn to address the said inconsistencies at some level. Even though the act is debatable and multiple views are expressed on the situation, this would be an opportunity to have a unified, all inclusive policy that will holistically address the concerns of urban development, accessibility, national security, land reclamation, environment management and many more disciplines.

\section{DIFFERENCES IN PERCEPTIONS: GAPS BETWEEN INGROUND SITUATIONS AND RESEARCH OBJECTIVES}

The differences in perceptions among research groups, policy makers and the society lead to have differences in the framing of problem situations and thus, widen the gap between them. This difference is manifested in the definitions, the research studies and the policy implications in urban development. The effectiveness of any policy depends upon the extent to which the means and bounds of the subject it deals with is clearly defined. In urban development, the policies often find 
difficulties with the definitions associated with them. The definition of an 'urban area' is one of the foremost areas of uncertainty in Sri Lanka (Indrasiri, 2000). In the absence of a commonly agreed definition, each agency selects its own criterion to define an urban area. Urban Development Authority defines all spatial entities that have been declared by a Gazette notification by the minister concerned as urban areas ${ }^{10}$. The Census and Statistics Department considers all areas under Municipal Council and Urban Council jurisdictions as urban areas ${ }^{11}$. There are other organizations that considers relatively more densely populated localities as urban units ${ }^{12}$.

Variations in definitions produce inconsistencies in information. For example, according to the figures of census 1981 and 2001, the percentage urban population in Sri Lanka had drastically declined by nearly fifty percent within that period. This was due to the merger of the local administration units known as 'Town Councils' and 'Gam Sabhas' to introduce 'Pradeshiya Sabhas' in 1980s under local government reforms. Since the definitions of the Census and Statistics remained the same, Town Council areas were considered to be 'rural' along with Pradeshiya Sabhas and the results presented a confusing reverse trend in urbanization in the island. At the same time, the Urban Development Authority's declaration of urban areas is based very much on timely requirements, but not on widely known criterion. Similar inexplicitness is observable in the declaration of municipal and urban status of local areas for local government purposes. Thus, from an objective point of view, some of the highly populated and already urbanized areas may still remain undeclared $^{13}$, while the highly agriculture based settings with rural character might have already got urban status $^{14}$. This notes a serious gap between the ground situation and policy perception and this gap needs to be mended through research on this matter, but still has not interested many.

Related to the above, there is another problem associated with the urban local government sector in Sri Lanka. 'Urban' areas according to currently effectuated local government policies are the spatial entities under Municipal Councils and Urban Councils. They have been carved out of the heterogeneous landscapes of the country and their boundaries are rigidly delineated considering only a few factors such as the concentration of population, activities and strategic importance (Munasinghe, 2007). This system of local governance was a gift of British colonial ruling which adopted nothing more than the model then available in UK. Within this system, within a locality of certain size, the area where the non-agricultural activities are mostly concentrated are declared either as 'municipal' or 'urban' and the balance is left out as 'rural'. The interdependence and the integrated nature of the geographic elements are not that importantly considered. In the present day context, the local authorities experience enormous management difficulties due to the inevitable growth of urban activities beyond the originally delineated boundaries, segregation of the spatial entity of the same functional unit into two or more local authority jurisdictions, and the problems in sharing of common resources between the urban and the adjacent rural local authority areas (Abhayawardhana et al.,1999). Except for minor changes in boundaries and a few cases of uplifting the status of local authorities, needy major reforms in the local government system to direct urban development in a desirable manner have never been a concern for research up to now. Instead, research studies on local government usually mark their point of departure accepting the status quo.

Planning of the development of a great majority of small and medium towns, spread in all parts of the island and experiencing a rapid growth over the last three decades is another area of importance for urban management, transportation and environment conservation. They all encountered a few common problems such as reclamation of low lying areas which have been their storm water retention sites, traffic congestion along main arteries, disorder in activities, etc. Each of these issues have throughout been perceived in isolation from each other and addressed in separate fora, although all these are the outcomes of changing urban forms. There is no explicit policy to address the issues in the urban form in planning of these towns except for general procedures and guidelines stipulated by the Urban Development Authority. In the absence of a clear policy, development plans prepared for these towns are largely prototypic and less attention has been paid to the uniqueness of each of these towns. The plans therefore, have been least capable of dealing with the said problems. In a recent development, addressing some of these issues, the Ministry of Environment \& Natural Resources ventured the 'Haritha Lanka' programme (2010), in which planning and designing of Green Cities for health \& prosperity has been identified as a key unit. Notwithstanding the value of the concept, the means and ways of 'greening' these towns is an area of many uncertainties that needs more attention. However, on the other hand, urban development agencies have adequate information on these towns, they are equipped with research divisions, and the need for better planning for urban development is often emphasized. What is not happening is broad-based, vision-oriented research, aiming to evolve strategic planning and design processes on appropriate urban forms. 
The main obstacle to bring these differences into a common framework is the less-orchestrated mode of channeling resources for research projects from different funding agents. When the funds are available through lateral links, as they mostly are nowadays, in order to secure financial grants and other resource allocations, project undertakers are compelled to fulfill specific requirements of funding agents rather than to cater to broad-based national or community needs. The policy makers and the funding agents usually come up with preconceived solutions for the problems perceived on their own and influence the orientation and the findings of research (Kingdon, 1984). The most possible way out of this situation is to encourage research institutions including universities to undertake projects within a long term research agenda rather than supporting to 'muddle though' with problem situations and policies. For such agendas, policies that are already in place such as the National Physical Planning Policy, are worth being given consideration as the basis to initiate new research.

\section{CONCLUSION}

As stated at the beginning, this paper was aiming only to examine a few issues that have propped up in three areas in urban development: urban management, transportation and adaptation to climate change effects. It must be noted that gaps in research and policy in urban development sector are not limited to these three aspects. The paper employed a simple rational model as a framework to organize its content, notwithstanding the fact that complex research-policy and social relationships may not be fully reflected through this model. However, the paper brought in to discussion a few difficulties that hinder the establishment of links between research communities, interest groups, policy makers and the society in relation to the issues in urban development. It has also indicated a few broad possibilities to overcome those difficulties. While the policy making, implementation and social interests are more likely to be in a 'Garbage Can' (Kingdon, 1984) that works with timely, opportunity based and dominated interests, rather than smooth long term envisioned, sequentially processed and objectively oriented goals, some possibilities are still there for better scenarios. The first among them is a general national policy to prioritize research areas in the field in order to draw interests of different agencies and individuals.

It is needless to say that high level coordination with the respective organizations of the other sectors in the country is necessary throughout the formulation of such a policy. The responsibility of formulation of the policy lies with the relevant apex bodies in the sector, mainly the Urban Development Authority, but in the present day context the Ministry of Defense could better instigate this task. The second is the vitalization of broader researchpolicy communities, involving research experts, political figures, bureaucrats and technocrats. Formalization of these communities will internalize many capabilities from different parties into a stronger nexus between research and policy. The third possibility is the encouragement of academic and other institutes to increasingly undertake priority areas of research. However, the obvious question that is left unanswered here is whether the state sector or the non state sector funding could be secured for a programme of that nature.

\section{Notes}

Several workshops, printed publications and website publications were hosted by UNDP Sri Lanka, Asia Foundation, Sevanatha and many other organizations during 2000-2010 on Good governance, Solid waste management, etc.

2 eg: The National Climate Change Adaptation Strategy, 2010 by Ministry of Environment; Mainstreaming Climate Change Adaptation, 2010 by Institute of Policy Studies.

3 National Policy on Local Government: Extraordinary Gazette of the Democratic Socialist Republic of Sri Lanka: No: 1632/26- $18^{\text {th }}$ December 2009.

4 All local authorities are provided with a mandate to plan and regulate the developments in the areas under their jurisdictions by the Municipal Councils Ordinance No 17 of 1865, Urban Council Ordinance No 61 of 1939, and Pradeshiya Sabhas Act No 15 of 1987.

5 "In the development of road networks in urban centres consideration will be given to the separation of pedestrians and other slow moving traffic from the fast moving traffic and also to provide for parking of vehicles and for stopping of buses, with the least inconvenience to through traffic. These considerations will specially apply to National highways passing through such urban centres." - National Physical Plan, 2007, NPPD, Sri Lanka.

6 The Urban Design Studio work in years 2007-2010, carried out in some segments of streets in Colombo and a few other urban areas in Sri Lanka by Town \& Country Planning undergraduates of the University of Moratuwa.

7 National Policy on Solid Waste Management 2000 (http://www. environmentmin.gov.lk/policies.htm)

8 The Supreme Court of Sri Lanka decided on $14^{\text {th }}$ October 2008 that levying charges for polythene bags which were issued free to consumers with the goods they buy was illegal and directed the Attorney General to issue an order to the Consumer Affairs Authority directing supermarkets to stop levying charges for polythene bags within seven days. This directive was made when fundamental rights petition filed by Liyanagamage Ariyapala of Kottegoda, Matara stating that consumers' rights were violated by the action of the supermarkets and sought a directive to the Consumer Protection Authority to formulate guidelines on the dispensing of such bags at Supermarkets as well as in other retail outlets. Chief Justice 
pointed out that levying a charge for polythene bags or any other receptacle was illegal stating it amounted to pilfering public money. The counsellor representing the Minister of Environment told court that a levy of polythene bags was made to protect the environment.

9 Road Development Authority is currently processing the feasibility studies of the Kandy Expressway. It was indicated that a few foreign investors had shown interest to invest in this project.

${ }^{10}$ Definition of an Urban Area as indicated in Urban Development Authority Law No 47 of 1978, amended in 1983.

${ }^{11}$ http://www.statistics.gov.lk/PopHouSat/Year=2001

${ }_{12}$ Ministry of Urban Development and Sacred Area Development, 2006- Committee report on the development of urban pockets, not declared under UDA Law.

${ }^{13}$ Kaduwela, Dambulla, Kathankudi and Akkareipattu, Boralesgamuwa and Kesbewa which remained as Pradeshiya Sabhas but had rapidly urbanized over the last three decades, have been recently upgraded either to Municipal or to Urban status. Some examples that still remain with the same status are Panadura, Pilimathalawa, Ambalanthota and Mahara.

${ }^{14}$ Municipal status of Mathale, Matara, Gampaha and the urban status of Haputhale, Badulla and Ampara are questionable when compared to the population concentration, built up area and the size of the nonagro based economy of the places mentioned in Note13 above.

\section{References}

1. Abhayawardhana, H. A. P., 1999. Report of the Commission of Inquiry on Local Government Reforms. Colombo: The Government Publication Bureau.

2. Bandara, S., Lo, H. K. \& Wong, S. C., 2006. Recent Advancements in Traffic Control \& Management. In: Proceedings of Second International Conference on Transport \& Logistics Systems, Colombo, 21-22 August.

3. Clay E. \& Schaffer, B., 1984. Room for Maneuver: An Exploration of Public Policy in Agriculture and Rural Development. London: Heinemann.

4. Diandas, J., 1995. Transport and Urban Policy: Town Planning for Mobility of People. In: Towards an Urban Policy in Sri Lanka, L. S. Perera, K. L. Gunaratna, eds. Colombo: Institute of Town Planners Sri Lanka.

5. EMBARQ, 2009. Feasibility Report on Bus Rapid Transit for City of Colombo. Colombo: Ministry of Transportation.

6. Emmanuel, R., 1995. Energy-efficient Urban Design Guidelines for Warm-humid Cities: Strategies for Colombo, Sri Lanka. Journal of Architectural \& Planning Research, 12(1) pp. $58-75$.
7. Gunaratna, K. L., 2006. Spatial Concerns in Development: A Sri Lankan Perspective. New Delhi: Atlantic Publishers.

8. Hall, P., 1990. Policy Paradigms, Experts and the State: The Case of Macro-economic Policy making in Britain. In: S. Brooks and A. G. Gagnon, eds. Social Scientists, Policy and State. New York: Praeger.

9. Indrasiri, L. H., 2000. Redefining of Urban Centres and Urbanization in Sri Lanka. Centre for National Physical Planning, Sri Lanka.

10. Kingdon, J., 1984. Agendas, Alternatives and Public Policies. New York: Harper/Collins.

11. Kumarage, A. S., 2004. Bus and Rail Choice Model for the Colombo Metropolitan Region. Annual Sessions, Institution of Engineers, Sri Lanka.

12. Kumarage, A. S., 2011. What you should know about oneway traffic systems. The Sunday Times, July 17, 2011.

13. Kurukulasuriya, V., 1997. Fifty Years of Town \& Country Planning in Sri Lanka. Colombo: Department of Town \& Country Planning.

14. Leda, H., 2010. Sustainable Urban Transport in an Asian Context. Tokyo: Spring.

15. Munasinghe,J.N.,2007.InternationalizinginaNationalizing Context: Rethinking History of Contemporary Town Planning in Sri Lanka. In: Proceedings of $9^{\text {th }}$ International Congress of Asian Planning Schools. Colombo 27-29August.

16. National Action Plan for Haritha Lanka Programme, 2009. Colombo: National Council for Sustainable Development.

17. National Physical Planning Policy, 2007. Colombo: National Physical Planning Department.

18. Oh, C. H., 1997. Explaining the Impact of Policy Information on Policy making, Knowledge and Policy: the International Journal of Knowledge Transfer and Utilization, 10(3), pp. 25-55.

19. Perera, A., 2011. Cash for Trash, Leaders in Advocacy Programme, 22 - 23 January, 2011. Univerity of Colombo.

20. Perera, L. S. \& Gunaratna, K. L., 1995. Towards an Urban Policy for Sri Lanka. Colombo: Institute of Town Planners Sri Lanka.

21. Self, P., 1985. Political Theories of Modern Government: Its Role and Reform. London: Allen and Unwin. 
22. Urban Development Authority, 2001. 'Traffic and Transport Plan for City of Colombo', Unpublished Report.

23. Urban Sector Policy Action Plan, 1998. Colombo: Urban Development Authority.
24. Walt, G., 1994. How far does Research Influence Policy. European Journal of Public Health, 4, pp. 233-35.

25. Weiss, C. H., 1991, Policy Research as Advocacy: Pro and Con, Knowledge and Policy. The International Journal of Knowledge Transfer, 4(1), pp. 37-55. 